Slavica

bruxellensia

\section{Slavica bruxellensia}

Revue polyphonique de littérature, culture et histoire

slaves

12 | 2016

Miniatures

\title{
Cœuré S., Pierre Pascal. La Russie entre christianisme et communisme
}

\author{
Laurent Béghin
}

\section{OpenEdition}

Journals

Édition électronique

URL : http://journals.openedition.org/slavica/1808

DOI : $10.4000 /$ slavica. 1808

ISSN : 2034-6395

\section{Éditeur}

Université libre de Bruxelles - ULB

\section{Référence électronique}

Laurent Béghin, «Cœuré S., Pierre Pascal. La Russie entre christianisme et communisme », Slavica bruxellensia [En ligne], 12 | 2016, mis en ligne le, consulté le 23 septembre 2020. URL : http:// journals.openedition.org/slavica/1808; DOI : https://doi.org/10.4000/slavica.1808

Ce document a été généré automatiquement le 23 septembre 2020.

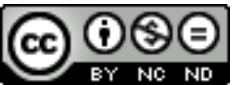

Les contenus de Slavica bruxellensia sont mis à disposition selon les termes de la Licence Creative Commons Attribution - Pas d'Utilisation Commerciale - Pas de Modification 3.0 France. 


\title{
Cœuré S., Pierre Pascal. La Russie entre christianisme et communisme
}

\author{
Laurent Béghin
}

\section{RÉFÉRENCE}

Cœuré S., Pierre Pascal. La Russie entre christianisme et communisme, Lausanne, Les Éditions Noir sur Blanc, 2014, 415 p.

1 Fin connaisseur de Dostoevskij, traducteur infatigable, grand professeur, Pierre Pascal (1890-1983) est une figure de proue de la slavistique française du XX $\mathrm{X}^{\mathrm{e}}$ siècle. Depuis qu'il avait publié ses journaux intimes dans les années 1970, on savait aussi qu'il avait été un témoin privilégié de la révolution russe et que son importance ne se bornait pas à ses mérites scientifiques. Si Georges Nivat et François Furet lui avaient consacré quelques belles pages ${ }^{1}$, l'homme conservait toutefois une part de mystère. On le connaît désormais mieux grâce à la riche monographie de Sophie Cœuré.

2 Pascal découvre sa vocation à la faveur d'un éphémère cours de langue russe institué, alliance franco-russe oblige, dans son lycée parisien. Reçu à l'École normale supérieure en 1910, il suit les leçons de Paul Boyer à l'INALCO. En 1911, la préparation d'un mémoire sur Joseph de Maistre et la Russie lui offre l'occasion d'un premier voyage à Kiev, Moscou et Saint-Pétersbourg. L'été suivant, la visite du monastère d'Optino et d'une communauté tolstoïenne l'enthousiasme. C'est que le jeune homme, qui, contrairement à sa famille très attachée à la III $^{\mathrm{e}}$ République, est un fervent catholique acquis aux idées de l'abbé Portal sur l'union des Églises, voit dans la Russie un antidote à cette France bourgeoise et parlementaire qu'il abhorre.

3 Grièvement blessé à deux reprises au commencement de la guerre, le lieutenant Pascal est affecté à la mission militaire française envoyée à Petrograd au printemps 1916 afin de soutenir l'effort de guerre de l'allié russe. Sans jamais renier le christianisme, il subit l'attraction du bolchevisme et décide, en 1918, de désobéir à sa hiérarchie et de rester en Russie. Un moment agent de la Tcheka, il travaille ensuite pour Georgij Čičerine au 
commissariat du peuple aux Affaires étrangères, puis à l'Internationale communiste. Bientôt déçu par la bureaucratisation de la révolution, accusé de sympathies anarchisantes (à Moscou, il fréquente Boris Souvarine et Victor Serge), suspecté en raison de son catholicisme, Pascal est relevé de ses fonctions au Komintern. Pour vivre, il traduit en français un choix d'œuvres de Lénine et accepte un poste d'archiviste à l'Institut Marx-et-Engels, dont il sera révoqué en 1931 pour raisons politiques. Deux ans plus tard, il rentre à Paris grâce à une intervention de Boyer et entame une carrière universitaire qui, après la soutenance de sa thèse sur Avvakum et les débuts du Raskol (1938), le conduira jusqu'en Sorbonne. Après la guerre, il mena en outre un combat discret contre le totalitarisme soviétique, collaborant à Preuves, chroniquant pour diverses revues, des ouvrages hostiles à l'URSS, défendant les œuvres de Pasternak, Sinjavskij et Solženicyn.

«Le regard que nous portons sur le peuple soviétique, comme sur les militants de l'Internationale communiste, n'est désormais ni celui de la condamnation, ni celui de la justification: c'est celui de la compréhension ", écrit Sophie Cœuré au seuil de son étude (p. 8). Fidèle à ce principe, l'historienne française nous livre une biographie détaillée et sans parti-pris, basée sur l'exploitation des notes que le slavisant n'a cessé de prendre dès son arrivée à Petrograd en 1916 ainsi que de nombreux documents d'archive inédits conservés en France et en Russie. Elle ne craint pas d'aborder les aspects les plus embarrassants de l'itinéraire idéologique de Pascal, comme son approbation inconditionnelle, au commencement de la révolution, de la terreur rouge, son éloge des premiers camps de concentration (pp. 168-169) ou son mépris, au début des années vingt, d'intellectuels hostiles au régime (pp.172-173). On regrettera cependant qu'elle n'envisage guère son œuvre proprement universitaire et son travail, pourtant colossal, de médiateur culturel. Notons enfin que le livre est agrémenté d'un cahier photographique et d'un index des noms cités.

\section{NOTES}

1. Georges Nivat, «Un russophile... Pierre Pascal», in Idem, Vers la fin du mythe russe. Essais sur la culture russe de Gogol à nos jours, L’Âge d'Homme, Lausanne, 1988, pp. 180-188. François Furet, Le passé d'une illusion. Essai sur l'idée communiste au XXe siècle, Paris, Le Livre de Poche, 1996 (1 ère éd. Robert Laffont /Calmann Lévy, 1995), pp. 164-185. 


\section{AUTEURS}

\section{LAURENT BÉGHIN}

Université Saint-Louis Bruxelles, Faculté de traduction et d'interprétation Marie Haps 